\title{
Multi-objective optimization of process parameters during low-pressure die casting of AZ91D magnesium alloy wheel castings
}

\author{
Chen Zhang, Yu Fu, Han Wang, and *Hai Hao \\ Key Laboratory of Solidification Control and Digital Preparation Technology of Liaoning Province, School of Materials Science and Engineering, \\ Dalian University of Technology, Dalian 116024, China.
}

\begin{abstract}
Multi-objective optimization has been increasingly applied in engineering where optimal decisions need to be made in the presence of trade-offs between two or more objectives. Minimizing the volume of shrinkage porosity, while reducing the secondary dendritic arm spacing of a wheel casting during low-pressure die casting (LPDC) process, was taken as an example of such problem. A commercial simulation software ProCAST $^{\mathrm{TM}}$ was applied to simulate the filling and solidification processes. Additionally, a program for integrating the optimization algorithm with numerical simulation was developed based on SiPESC. By setting pouring temperature and filling pressure as design variables, shrinkage porosity and secondary dendritic arm spacing as objective variables, the multi-objective optimization of minimum volume of shrinkage porosity and secondary dendritic arm spacing was achieved. The optimal combination of AZ91D wheel casting was: pouring temperature $689{ }^{\circ} \mathrm{C}$ and filling pressure $6.5 \mathrm{kPa}$. The predicted values decreased from $4.1 \%$ to $2.1 \%$ for shrinkage porosity, and $88.5 \mu \mathrm{m}$ to $81.2 \mu \mathrm{m}$ for the secondary dendritic arm spacing. The optimal results proved the feasibility of the developed program in multi-objective optimization.
\end{abstract}

Key words: magnesium alloy; multi-objective optimization; process parameters; shrinkage porosity; secondary dendritic arm spacing

CLC numbers: TG146.2/TP391.9 Document code: A Article ID: 1672-6421(2018)05-327-06

$\mathrm{W}$

heels are widely used in automotive applications ${ }^{[1]}$.

To achieve excellent mechanical properties, low pressure die casting (LPDC) process is applied to manufacture wheels. Many studies have been carried out on the optimization of the LPDC process for magnesium wheels ${ }^{[2-4]}$. Among these studies, it is common to use the traditional trial-and-error method. However, manual design, experiment and redesign take up too much time and yet may not obtain the optimal designs. To meet the requirements of high-efficiency and high-quality design, an automatic multi-objective optimization program based on SiPESC (i.e. Software Integration Platform for Engineering and Scientific Computation) was developed ${ }^{[5]}$. Multi-objective optimization is concerned with problems involving more than two objectives to be optimized simultaneously ${ }^{[6]}$. With SiPESC as the

\footnotetext{
*Hai Hao
}

Male, born in 1969, Professor. His research interests mainly focus on magnesium alloys and numerical simulation.

E-mail: haohai@dlut.edu.cn

Received: 2018-05-18; Accepted: 2018-07-05 support platform, it can achieve automatic updates of process parameters and numerical optimization during the whole LPDC process, facilitating the selection of optimal parameters combinations ${ }^{[7]}$. ProCAST was used to simulate the LPDC process of an AZ91D magnesium alloy wheel casting. Numerical simulations were performed to investigate the effects of pouring temperature and filling pressure on shrinkage porosity and secondary dendritic arm spacing, and therefore to identify the optimal combination of process parameters during the LPDC process. Thus, the capabilities of an automatic multi-objective optimization program based on SiPESC were highlighted.

\section{Steps of LPDC simulation}

\subsection{Geometric and finite element models}

The wheel model with the height of $160 \mathrm{~mm}$ and diameter of $420 \mathrm{~mm}$ was designed by UG software, as shown in Fig. 1(a). The body had a regular outer shape and internal hollow structure, and the thinnest part of the wheel casting was $5 \mathrm{~mm}$. The wheel model was meshed 
into $5 \mathrm{~mm}$ and the three-dimensional 4-node linear tetrahedral elements were adopted in the finite element model. The mesh generation results can be seen in Fig. 1(b), in which the element number was 167,494 . The casting die was meshed into $10 \mathrm{~mm}$, with 136,349 element number. The entire grid was exported to the ProCAST to perform LPDC simulation.
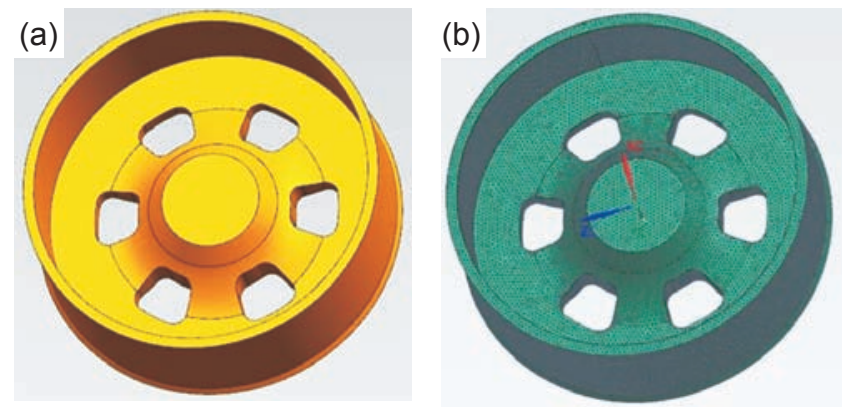

Fig. 1: (a) Geometry of wheel

(b) Finite element mesh of wheel

\subsection{Initial and boundary conditions}

A typical AZ91D magnesium alloy with the composition given in Table 1 was studied. The initial and boundary conditions used in the present simulation are as follows: the density of the alloy at room temperature is $1,820 \mathrm{~kg} \cdot \mathrm{m}^{-3}$, the liquidus is $602{ }^{\circ} \mathrm{C}$, and the solidus is $422^{\circ} \mathrm{C}$. The casting die is steel H13; its density is $7,625 \mathrm{~kg} \cdot \mathrm{m}^{-3}$. The thermal conductivity and the specific heat of the casting and die at different temperatures are in accordance with the commercial ProCAST database. To ensure the sequence solidification, the initial temperature of the side die, top die, and bottom die are $360^{\circ} \mathrm{C}, 380^{\circ} \mathrm{C}$ and $400{ }^{\circ} \mathrm{C}$, respectively.

Table 1: Chemical composition of AZ91D magnesium alloy (wt.\%)

\begin{tabular}{|cccccccc} 
Al & $\mathrm{Zn}$ & $\mathrm{Mn}$ & $\mathrm{Si}$ & $\mathrm{Cu}$ & $\mathrm{Ni}$ & $\mathrm{Fe}$ & $\mathrm{Mg}$ \\
\hline 9.06 & 0.55 & 0.28 & 0.03 & 0.02 & 0.0035 & 0.004 & Bal.
\end{tabular}

Various stages during the LPDC process include: ABascending stage, $\mathrm{BC}$-filling stage, $\mathrm{CD}$-boosting stage, $\mathrm{DE}$ maintaining stage, and EF-releasing stage, as shown in Fig. 2. The initial pressure parameters were calculated according to the Handbook of Casting Forming ${ }^{[8]}$.

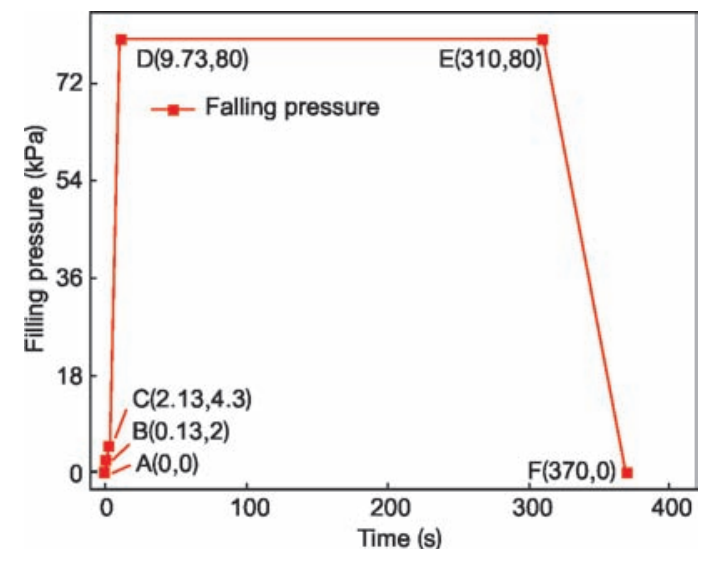

Fig. 2: Typical pressure curve of LPDC process of AZ91D alloy

\subsection{Determination of process parameters and objectives}

Process parameters such as pouring temperature, filling pressure and pressure holding time, are crucial to casting quality. The first parameter to be decided is pouring temperature; its value range is established based on experiments. The reasonable range of pouring temperature for AZ91D is set from $680^{\circ} \mathrm{C}$ to $720^{\circ} \mathrm{C}^{[9,10]}$. Another process parameter to be decided is filling pressure. Filling pressure is applied to push the molten metal into the die ${ }^{[11]}$. It can be calculated by Pascal's law, as shown in Eq. (1):

$$
P=\frac{h \rho k}{10200}
$$

where $\rho$ is the density of the molten metal, $\mathrm{k}$ is constant 1.5 , and $h$ is the height difference between the surface of the melt and the top of the feeding tube, varying from $16 \mathrm{~cm}$ to $30 \mathrm{~cm}$. The minimum filling pressure required to overcome the $16 \mathrm{~cm}$ metal pressure in the tube is calculated to be $4.3 \mathrm{kPa}$. The range of filling pressure is set between $4.3 \mathrm{kPa}$ and $8.0 \mathrm{kPa}$. In casting design, there are two main objectives: eliminating casting defects and maximizing yield strength ${ }^{[12,}{ }^{13]}$. In this study, pouring temperature and filling pressure are selected to be the design variables, the objectives are characterized by the volume of shrinkage porosity and secondary dendritic arm spacing in the region between the spoke and the rim.

\section{LPDC simulation with SiPESC}

\subsection{Automatic optimization workflow}

To begin, the finite element model of the wheel casting was exported from UG software, then the entity grid was imported into ProCAST. During the whole process, the input parameters were modified according to the specified optimization algorithm implemented on SiPESC. After each simulation on ProCAST, the value of the output parameter was read, then whether the objective was optimal or not was determined. If the objective was optimal, the optimization was completed. Otherwise, the input parameters were modified and reiterated until the ideal target value was achieved ${ }^{[14]}$. The workflow is shown in Fig. 3.

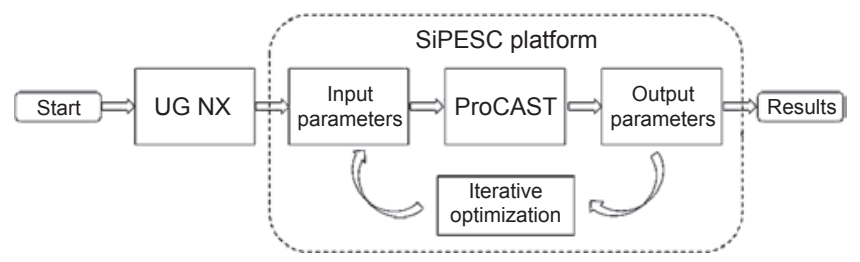

Fig. 3: Workflow of automatic optimization on SiPESC

\subsection{Data exchange}

Optimization of the process requires data exchange, which was realized through file transfer. The challenge was to run a sequence of simulations with multi-input parameters on the ProCAST backstage. The process parameters were written into an input file (preprocessing.py), then ProCAST software executed batch command (*.bat) to run the simulation. Finally, 
the results were written into an output file (postprocessing. py). The JavaScript programming language was used to compile the program. Based on SiPESC, update script (Update. js) was used to obtain each new response value which would later lead to the change of input process parameters; optimize script (Optimize.js) was used to select the proper optimization algorithm regarding the specified problem. Through the entire iterative process, automatic multi-objective optimization was achieved. The framework of multi-objective optimization of the LPDC process is shown in Fig. 4. The result can be stored and obtained through free Sqliteman software.

\subsection{Optimization algorithm}

During the LPDC process, the filling speed is relatively slow, so the laminar flow model is used. The corresponding momentum and energy equations are given in Eq. (2)-(5):

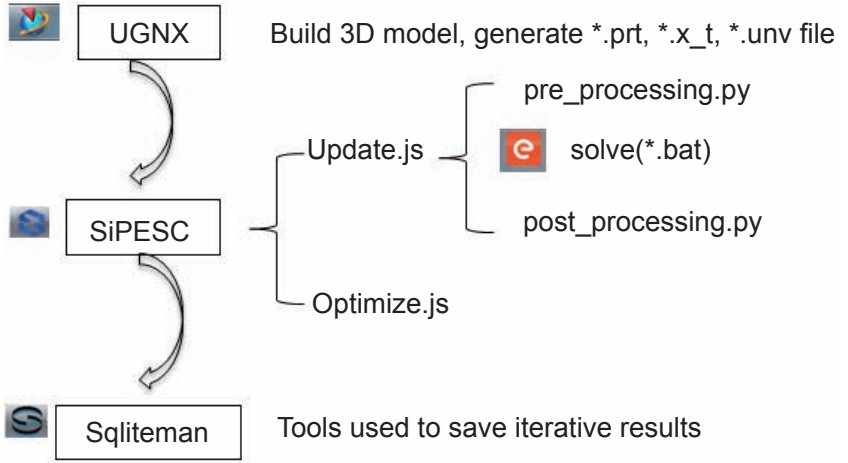

Fig. 4: Optimization of LPDC process parameters

$$
\begin{gathered}
\frac{\partial u}{\partial t}=g_{x}-\frac{1}{\rho} \cdot \frac{\partial p}{\partial x}-\left\{u \frac{\partial u}{\partial x}+v \frac{\partial u}{\partial y}+\omega \frac{\partial u}{\partial z}+r\left[\frac{\partial^{2} u}{\partial x^{2}}+\frac{\partial^{2} u}{\partial y^{2}}+\frac{\partial^{2} u}{\partial z^{2}}\right]\right\} \\
\frac{\partial v}{\partial t}=g_{y}-\frac{1}{\rho} \cdot \frac{\partial p}{\partial y}-\left\{u \frac{\partial v}{\partial x}+v \frac{\partial v}{\partial y}+\omega \frac{\partial v}{\partial z}+r\left[\frac{\partial^{2} v}{\partial x^{2}}+\frac{\partial^{2} v}{\partial y^{2}}+\frac{\partial^{2} v}{\partial z^{2}}\right]\right\} \\
\frac{\partial \omega}{\partial t}=g_{z}-\frac{1}{\rho} \cdot \frac{\partial p}{\partial z}-\left\{u \frac{\partial \omega}{\partial x}+v \frac{\partial \omega}{\partial y}+\omega \frac{\partial \omega}{\partial z}+r\left[\frac{\partial^{2} \omega}{\partial x^{2}}+\frac{\partial^{2} \omega}{\partial y^{2}}+\frac{\partial^{2} \omega}{\partial z^{2}}\right]\right\} \\
\rho_{\varphi}\left\{u \frac{\partial y}{\partial x}+v \frac{\delta y}{\delta x}+\omega \frac{\delta y}{\delta x}+\frac{\delta y}{\delta x}\right\}=\frac{\partial}{\partial x}\left\{\lambda \frac{\partial T}{\partial x}\right\}+\frac{\partial}{\partial y}\left\{\lambda \frac{\partial T}{\partial y}\right\}+\frac{\partial}{\partial z}\left\{\lambda \frac{\partial T}{\partial z}\right\}+\frac{\partial T}{\partial t}
\end{gathered}
$$

where

$u, v, w$ - velocity vectors, $\mathrm{m} \cdot \mathrm{s}^{-1}$;

$x, y, z$ - coordinate component;

$p$ - the pressure per unit density, $\mathrm{Pa}$;

$v$ - viscosity, $\mathrm{m}^{2} \cdot \mathrm{s}^{-1}$

$g_{x}, g_{y}, g_{z}-$ gravity component in each direction, $\mathrm{m} \cdot \mathrm{s}^{-2}$;

$t$ - filling time, s;

$T$ - temperature, ${ }^{\circ} \mathrm{C}$;

$\rho$ - density, $\mathrm{kg} \cdot \mathrm{m}^{-3}$;

$\lambda$ - thermal conductivity, $\mathrm{W} \cdot(\mathrm{m} \cdot \mathrm{K})^{-1}$;

$F$ - fluid volume, ml.

Ant colony optimization (ACO) algorithm was used as the optimization algorithm ${ }^{[15,16]}$. ACO is one of the search and global optimization methods that has the advantage of solving complex coupling problems. The process variables change automatically according to the following rules: (1) The start and end variables can only be calculated once; (2) The more intense the increments between two calculations, the greater the probability that it will be selected.

Since a shrinkage porosity-free casting is always desired, the porosity requirement was $\mathrm{SP}(x)=0 \%$. The secondary dendritic arm spacing $\operatorname{SDAS}(x)$ is not defined due to the unlimited value. The optimization problem was defined as follows: Minimize $f(x)=[\mathrm{SP}(x), \operatorname{SDAS}(x)]$, subject to $g(x)=[\mathrm{SP}(x)=0]$, where $x$ $=[T, P] T, 680 \leqslant T \leqslant 720^{\circ} \mathrm{C}, 4.3 \mathrm{kPa} \leqslant P \leqslant 8.0 \mathrm{kPa}$. The focus was primarily on the automatic optimization where numerical simulation is employed to predict the values of the objective variables.

\section{Analyses of simulation results}

In order to analyze the effects of process parameters on microstructure, a single factor method was used. Two different process parameters, pouring temperature and filling pressure, were simulated by controlling design variables.

\subsection{Effect of pouring temperature on shrinkage porosity and microstructure}

Using the initial and boundary conditions mentioned above, the calculations have been done for LPDC process. Figure 5 shows that when the filling pressure was $4.3 \mathrm{kPa}$, the iterative results change with the increasing pouring temperature. The profiles of volume of shrinkage porosity and secondary dendritic arm spacing under different pouring temperatures were not similar. The pouring temperature had a greater influence on the secondary dendritic arm spacing. With the pouring temperature increasing from $680{ }^{\circ} \mathrm{C}$ to $720^{\circ} \mathrm{C}$, the secondary dendritic arm spacing increased from $87.5 \mu \mathrm{m}$ to $93.7 \mu \mathrm{m}$.

When the pouring temperature was above $691^{\circ} \mathrm{C}$, the tendency to shrinkage gradually increased with an increase in pouring temperature, while the microstructure was coarsened. When the pouring temperature was lower than $691{ }^{\circ} \mathrm{C}$, the liquid flow-ability was reduced, thus weakening the feeding capacity, increasing the tendency to shrinkage porosity, the phenomenon especially common in thin-wall pieces ${ }^{[17]}$. Therefore, to facilitate the formation of the thin-walled components of magnesium alloy, the pouring temperature should be higher; whilst to reduce the tendency of shrinkage porosity, the pouring 


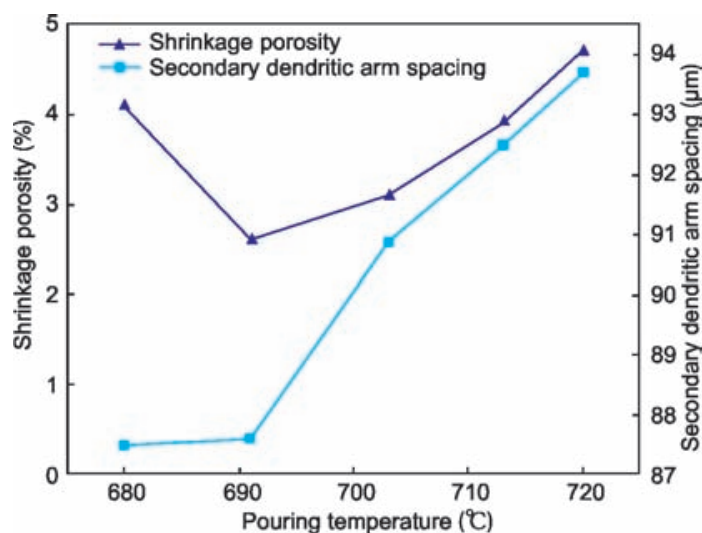

Fig. 5: Effect of pouring temperature on shrinkage porosity and secondary dendritic arm spacing

temperature should be as low as possible. Under this condition, the optimal pouring temperature was $691{ }^{\circ} \mathrm{C}$.

\subsection{Effect of filling pressure on shrinkage porosity and microstructure}

When the pouring temperature was $691{ }^{\circ} \mathrm{C}$, the change of objective variables with the filling pressure is shown in Fig. 6. It can be seen that with the filling pressure increasing from $4.3 \mathrm{kPa}$ to $8.0 \mathrm{kPa}$, the secondary dendritic arm spacing decreased from $87.6 \mu \mathrm{m}$ to $81.9 \mu \mathrm{m}$. The results, calculated with numerical simulation, showed a good correspondence with previous research $^{[18]}$.

In the case where the pouring temperature is constant, the filling speed depends on the increasing rate of the gas pressure acting on the surface of the alloy. The higher the filling pressure, the faster the filling speed. When the filling pressure was above

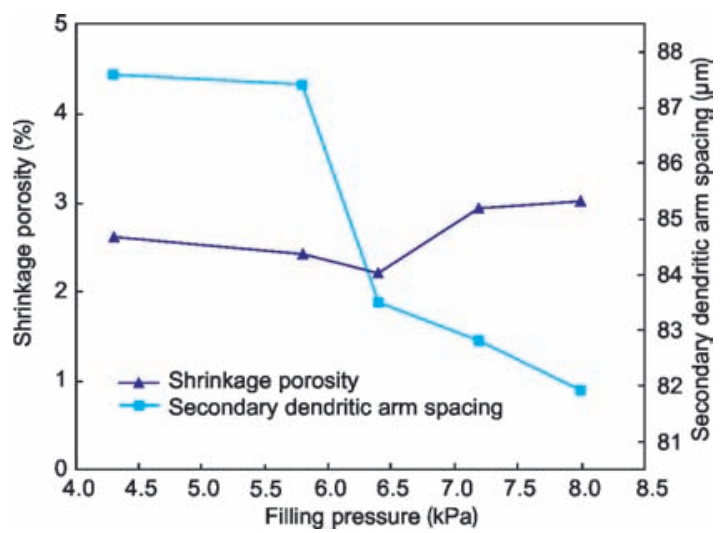

Fig. 6: Effect of filling pressure on shrinkage porosity and secondary dendritic arm spacing

$6.4 \mathrm{kPa}$, there will be shock splash in the cavity, resulting in porosity defects. Conversely, the lower the filling pressure, the slower the filling speed. When the filling pressure was lower than $6.4 \mathrm{kPa}$, the feeding capacity was restricted, which may also cause the shrinkage defects ${ }^{[19]}$.

\subsection{Combinational optimization results}

By setting pouring temperature and filling pressure as designed variables, the overall process during the filling and solidification stages of LPDC for an AZ91D wheel casting was numerically analyzed. The simulation results with optimized process parameters are shown in Table 2. The results show that the volume of shrinkage porosity after optimization can be improved from $4.1 \%$ to $2.1 \%$, and the secondary dendritic arm spacing can be shortened from $88.5 \mu \mathrm{m}$ to $81.2 \mu \mathrm{m}$.

Table 2: Combinational optimization of process parameters and corresponding predicted responses

$\begin{array}{ccccc}\text { Iteration } & \text { Pouring temperature }\left({ }^{\circ} \mathrm{C}\right) & \text { Filling pressure (kPa) } & \text { Shrinkage porosity (\%) } & \begin{array}{c}\text { Secondary dendritic arm } \\ \text { spacing }(\boldsymbol{\mu} \mathrm{m})\end{array} \\ 1 & 680 & 4.3 & 4.1 & 87.5 \\ 2 & 689 & 6.5 & 2.1 & 81.2 \\ 3 & 703 & 6.8 & 2.7 & 86.7 \\ 4 & 712 & 7.4 & 3.5 & 85.6 \\ 5 & 720 & 8.0 & 3.9 & 88.5\end{array}$

The optimum combination result of process parameters was pouring temperature of $689^{\circ} \mathrm{C}$ and filling pressure of $6.5 \mathrm{kPa}$. The whole filling process took approximately $6.2 \mathrm{~s}$. At the beginning, the liquid metal flowed smoothly into the center of the wheel. At $1.7 \mathrm{~s}$, the liquid metal reached the junctions between the rim and the spokes. At $2.8 \mathrm{~s}$, the liquid alloy joined together at the bottom of the rim, then the liquid alloy rose steadily and arrived at half height of the rim at $4.3 \mathrm{~s}$. At this moment, the temperature decreased to $640{ }^{\circ} \mathrm{C}$ and the alloy was still in fluid state. When the cavity was filled entirely, the temperature of the metal was above the liquidus $602{ }^{\circ} \mathrm{C}$. During the whole filling process, no splashes or misrun occurred, as shown in Fig. 7.
The LPDC simulation ceased at $400{ }^{\circ} \mathrm{C}$. When the cavity was filled with melted metal, the cavity was still in fluid state, and then it started to solidify. Figure 8 shows the distribution of solid fraction of the wheel casting during the solidification process of LPDC. The solidification started from the top of the rim to the bottom of the wheel, which ensured the sequence solidification during the whole process. The whole solidification process lasted around $401.5 \mathrm{~s}$.

Another combination of process parameters was selected to compare with the optimal result. Figure 9 and Fig. 10 show the final distribution of shrinkage porosity and contour of secondary dendritic arm spacing in the casting with different process 

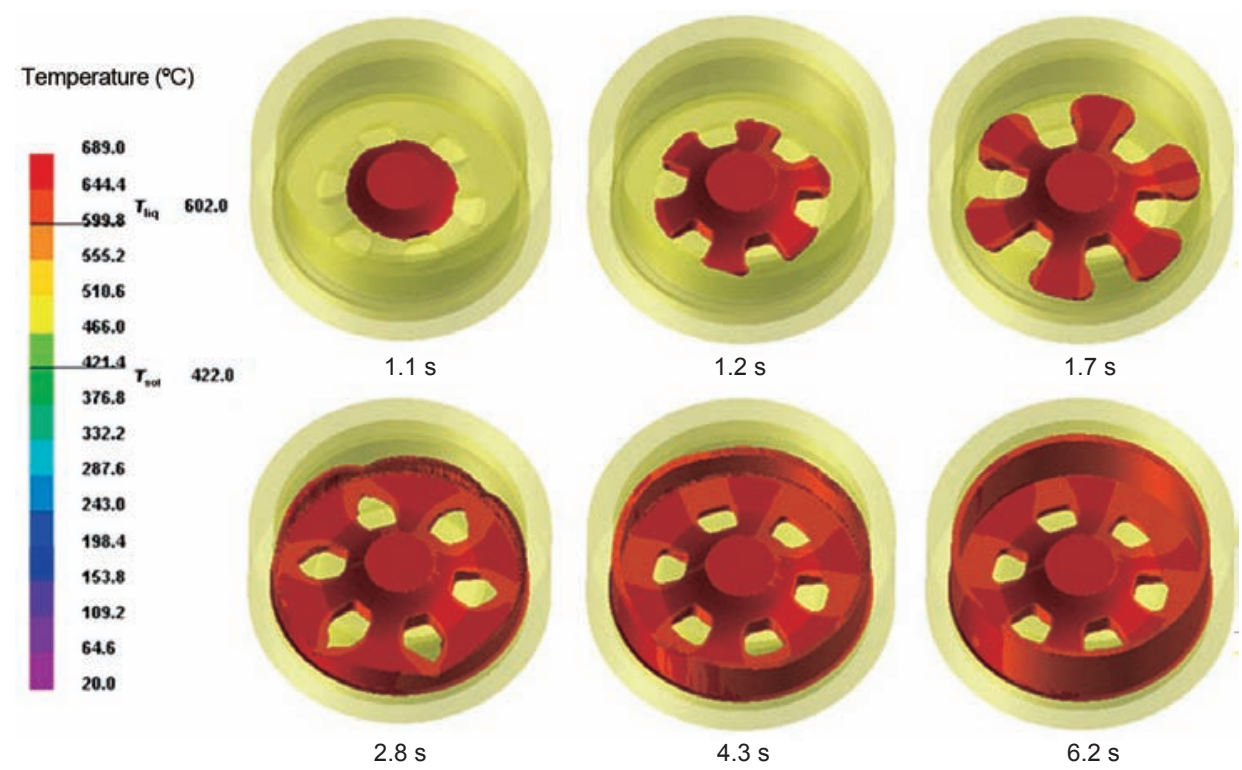

Fig. 7: Temperature distribution during filling process of LPDC at pouring temperature of $689^{\circ} \mathrm{C}$ and filling pressure of $6.5 \mathrm{kPa}$
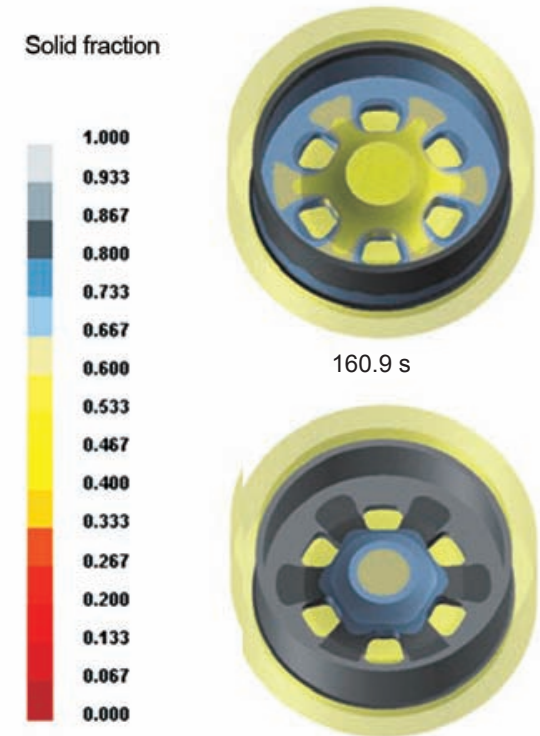

$160.9 \mathrm{~s}$

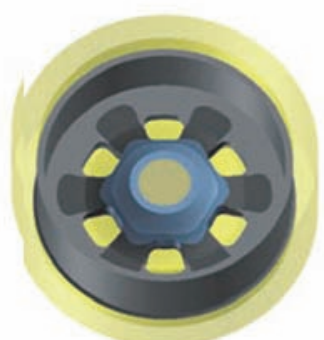

$320.6 \mathrm{~s}$

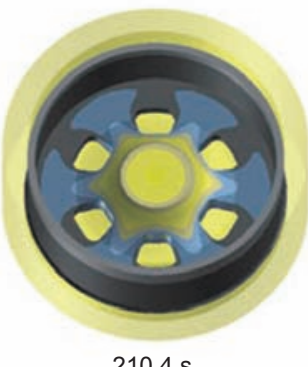

$210.4 \mathrm{~s}$

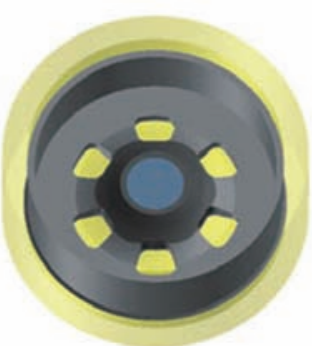

$375.2 \mathrm{~s}$

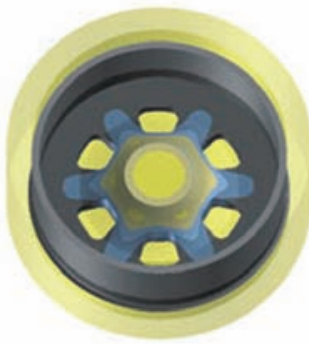

$260.8 s$

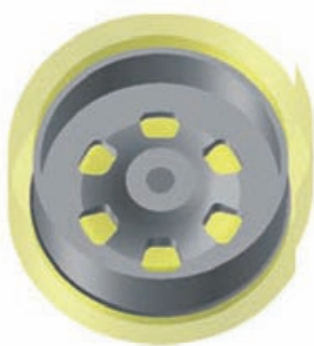

$401.5 \mathrm{~s}$

Fig. 8: Solid fraction during solidification process of LPDC at pouring temperature of $689^{\circ} \mathrm{C}$ and filling pressure of $6.5 \mathrm{kPa}$

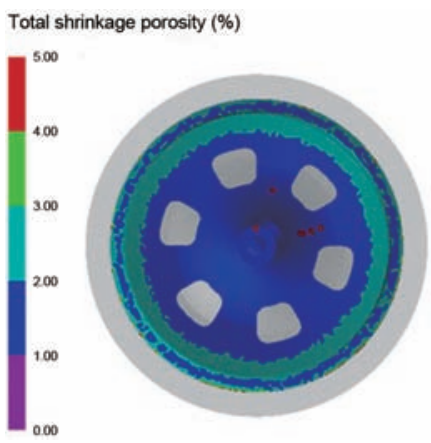

(a) $720^{\circ} \mathrm{C}, 8.0 \mathrm{kPa}$

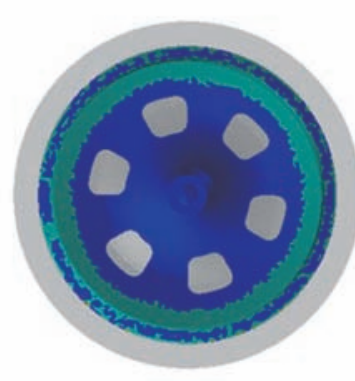

(b) $689^{\circ} \mathrm{C}, 6.5 \mathrm{kPa}$

Fig. 9: Comparison between results of shrinkage porosity before (a) and after optimization (b)

parameter combinations. It can be seen that shrinkage porosity mainly exists in the region between the rim and the spoke, which had the largest volume and remained liquid for a long period, whereas the other parts had moderate shrinkage porosity, as shown in Fig. 9. According to the theory of low-pressure die casting and production experience, the shrinkage of the casting is mainly caused by overheating. The thicker the part of the casting, the more likely the shrinkage porosity occurs. Because the change in wall thickness at the above location is relatively great, as the feeding channel of the casting is disconnected, the isolated liquid cannot be fed with the external liquid in time. The casting shrinks locally and causes local overheating of the casting, resulting in shrinkage porosity.

Moreover, the entire secondary dendritic arm spacing was 
Secondary dendritic arm spacing $(\mu \mathrm{m})$
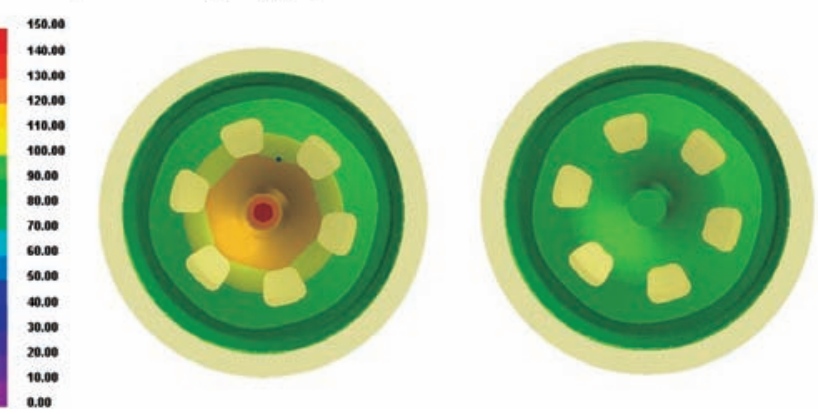

Fig. 10: Comparison between results of secondary dendritic arm spacing before (a) and after (b) optimization

refined by adopting the optimal process parameter, as can be seen in Fig. 10. With pouring temperature at $689{ }^{\circ} \mathrm{C}$ and filling pressure at $6.5 \mathrm{kPa}$, the volume of shrinkage porosity at the junctions was reduced to $2.1 \%$ and the secondary dendritic arm spacing was refined to $81.2 \mu \mathrm{m}$, thus the multi-objective optimization of LPDC process was achieved.

\section{Conclusions}

In this study, the proposed optimization program was developed to achieve multiple objectives automatically. Optimization of the LPDC process of AZ91D wheel casting was carried out on SiPESC using ACO algorithm. The program was designed to obtain an optimal combination between the shrinkage porosity and secondary dendritic arm spacing, which provided a reference for the selection of process parameters. The following conclusions can be drawn:

(1) Pouring temperature and filling pressure play major roles in LPDC process, both of which have greater influence on the secondary dendritic arm spacing than on the shrinkage porosity.

(2) With the optimal parameter combination, the predicted value for shrinkage porosity decreases from $4.1 \%$ to $2.1 \%$, while the secondary dendritic arm spacing is refined from 88.5 $\mu \mathrm{m}$ to $81.2 \mu \mathrm{m}$. The optimal results prove the feasibility of the developed program in multi-objective optimization.

(3) Results of optimization provide a reference to LPDC process for selection of optimal parameter combinations. In this study, the optimum combination of LPDC process was: pouring temperature of $689^{\circ} \mathrm{C}$ and filling pressure of $6.5 \mathrm{kPa}$.

\section{References}

[1] Kulekci M K. Magnesium and its alloys applications in automotive industry. International Journal of Advanced Manufacturing Technology, 2009, 39(9-10): 851-865.

[2] Luo A A. Magnesium casting technology for structural applications. Journal of Magnesium \& Alloys, 2013, 1(1): 2-22.
[3] Wang Y C, Li D Y, Peng Y H, et al. Numerical simulation of low pressure die casting of magnesium wheel. International Journal of Advanced Manufacturing Technology, 2007, 32(3-4): 257264.

[4] Su D W. Numerical Simulation and Technique Optimization of the Low Pressure Die Casting Process of Aluminum Alloys Automotive Wheel. Jiangsu University, 2008. (In Chinese)

[5] Chen B S. Advancements of Design and Development for SiPESC-a Software Integration Platform of Numerical Simulation. Science \& Technology Innovation Herald, 2016, 13 (19): 178-179.

[6] Kor J, Chen X, Sun Z, et al. Casting Design through Multiobjective Optimization. IFAC Proceedings Volumes, 2011, 44(1):11642-11647.

[7] Zhang H W, Chen B S, Li Y P, et al. Advancement of design and implementation of SiPESC for development of integrated CAE software system. Computer Aided Engineering, 2011, 20(2):3949. (In Chinese)

[8] Li X Y, Liu B C, Huang T Y, et al. Handbook of Casting Forming, Third ed., China Machine Press, Beijing, 2011. (In Chinese)

[9] Huang H, Fu P H, Peng L M, et al. Effect of Mould Temperature and Pouring Temperature on the Hot Tearing and Fluidity of AZ91D Magnesium Alloy. Special Casting \& Nonferrous Alloy, 2012, 1(1): 81-84. (In Chinese)

[10] Qiu K Q, Wang L, Liu B, et al. Numerical Simulation of Low Pressure Die Casting of Magnesium Alloy Car Wheel. Foundry, 2011, 60(12): 1214-1213. (In Chinese)

[11] Cohen T H, Glicksman M E. Development of an interactive simulation system for die cavity filling and its application to the operation of a low-pressure casting process. Modelling \& Simulation in Materials Science \& Engineering, 2000, 8(4): 583.

[12] Dubé D, Couture A, Carbonneau Y, et al. Secondary dendrite arm spacings in magnesium alloy AZ91D: from plaster moulding to laser remelting. Cast Metals, 1998, 11(3): 139-144.

[13] Zhang D F, Lan W, Ding P D, et al. Quantitative research on relationship between secondary dendrite arm spacing and solidification cooling rate of AZ91 magnesium alloy. Journal of Materials Engineering, 2007, 21(4): 23-26.

[14] Yang C F, Chen B S, Zhang S, et al. Design and implementation of general integrated optimization design software SiPESC. OPT. Computer Aided Engineering, 2011, 20(4): 42-48. (In Chinese)

[15] Stützle T. Ant Colony Optimization. Computational Intelligence Magazine IEEE, 2007, 1(4): 28-39.

[16] Yu Y D, Wang J R, Jiang $H$ Y, et al. Numerical Simulation of Filling and Solidification Processes for Magnesium Alloy in Low Pressure Cast Process. Hot working Technology, 2005(10): 2931. (In Chinese)

[17] Fu P H, Luo A A, Jiang $H$ Y, et al. Low-pressure die casting of magnesium alloy AM50: Response to process parameters. Journal of Materials Processing Tech, 2008, 205(1): 224-234.

[18] Jiang J F, Wang $Y$, Chen G, et al. Comparison of mechanical properties and microstructure of AZ91D alloy motorcycle wheels formed by die casting and double control forming. Materials \& Design, 2012, 40: 541-549.

[19] Hou L Q, Fan Y B, Qiao X M, et al. Casting Process Analysis and Die Design of Low-pressure Casting Magnesium Alloy Wheel-hub. Special Casting \& Nonferrous Alloys, 2015, 35(12): 1274-1276. (In Chinese)

This study was financially supported by the National Key Research and Development Program of China (Grant No. 2016YFB0701204). 